\title{
A Terra geme de agonia A Teologia da Criação a partir da denúncia profética ${ }^{1}$
}

\author{
Francisco Orofino ${ }^{2}$
}

\section{Introduzindo o assunto}

Quando procuramos fundamentos para uma espiritualidade ecológica temos a tendência de selecionar textos bíblicos que nos falem da natureza, das árvores e dos animais, algo que nos remeta às idéias meio românticas de um ser humano vivendo em total integração com o meio ambiente. Realisticamente, a Bíblia mostra a natureza em seu esplendor, mas não esconde o impacto causado pelo ser humano em sua necessidade de abrir espaço para poder sobreviver. A sobrevivência humana exige a derrubada de matas, controle de rios, ampliação das áreas agrícolas, pastos e construções. Na luta pela sobrevivência, qualquer grupo humano causa impacto ambiental. Na grande maioria destes grupos de caçadores e coletores, o impacto é facilmente absorvido pelo ambiente e rapidamente se restaura. Por exemplo, o impacto causado pelos yanomamis na Amazônia é nulo. Mas quando o impacto é grande e o contínuo uso das terras para a agricultura e pecuária impede a restauração das matas e florestas, a sociedade humana degrada o meio ambiente. Passa a haver risco de um colapso. $\mathrm{O}$ que pretendo refletir aqui é justamente a consciência bíblica deste colapso manifestada na pregação profética.

1 Este artigo se inspira no texto de MESTERS, Carlos \& OROFINO, Francisco, A Terra é nossa Mãe - Gênesis 1-12. São Leopoldo: CEBI, 2007.

2 Francisco Orofino é professor de Teologia Bíblica no Instituto de Teologia Paulo VI, em Nova Iguaçu, RJ. É diretor nacional do Centro de Estudos Bíblicos (CEBI) e assessor do ISER Assessoria. 
Quando procuramos textos ecológicos naturalmente nos voltamos para os textos iniciais do livro de Gênesis. Consideramos os textos sobre as origens e a criação do Universo e do ser humano, reunidos no Livro das Origens (Gn 1 a 11) como o protótipo do texto ecológico. Ora, Gênesis não reúne apenas textos que narram a criação. $\mathrm{O}$ livro, na verdade, dá maior enfoque à degradação da criação. Por isso mesmo, o texto principal deste livro é a narrativa do dilúvio que começa exatamente assim: "o Senhor viu que a maldade do homem era grande sobre a terra, e que era continuamente mau todo desígnio de seu coração." (Gn 6,5).

Os textos sobre a criação e degradação em conseqüência das sucessivas quedas da Humanidade, presentes no Livro das Origens, são como uma colcha de retalhos. Existem trechos muito antigos e trechos mais recentes. Há textos que, antes de serem escritos, tinham sido transmitidos oralmente desde tempos imemoráveis. Muitas vezes não dá para saber de que época é cada retalho. É provável, por exemplo, que a narrativa de Caim e Abel seja mais antiga que a narrativa Javista da criação em Gn 2-3. O que sabemos é a época em que a colcha foi costurada, a época em que o texto de Gênesis 1 a 11 foi composto e editado. Esta redação, de cunho sacerdotal, foi concluída no final do cativeiro da Babilônia, na segunda metade do século V antes de Cristo. É provável que, após o retorno para Judá, ele tenha recebido ainda alguns acréscimos.

Gênesis 1 a 11 é como uma parede feita com tijolos de todo tipo. Quem fez o muro tinha um desenho na cabeça que ele conseguiu expressar na parede usando aqueles tijolos todos: velhos e novos, grandes e pequenos, resistentes e frágeis, tudo misturado. O desenho é visível até hoje, e é bonito! O que nos interessa aqui não é tanto estudar o tamanho e a qualidade de cada tijolo ou pedra da parede, mas sim ver de perto o desenho que ele quis expressar e descobrir a mensagem que lá existe para nós.

Estas histórias sobre as origens nasceram da terra, dos problemas e das esperanças do povo de Deus. Originalmente, são respostas às perguntas que o povo se fazia a partir dos problemas mais caseiros. Foi a crise do exílio que transformou estes problemas caseiros em questões mais amplas. Vamos ver mais de perto o processo que originou, bem como a crise que provocou a composição deste texto de Gênesis 1 a 11 sobre a criação e o começo da humanidade. É um longo espaço de tempo, desde a pregação profética até a dura realidade do exílio. Mas, sem dúvida, este pequeno livro ajudou os exilados a redescobrir sua missão como povo de Deus. 


\title{
1. Os profetas apontam os primeiros sinais da crise
}

Uma crise nunca vem de repente, mas nasce aos poucos. Assim aconteceu com o povo de Deus. Depois de um longo tempo de reis e de independência, o povo se viu exilado, longe de sua terra. Mergulhado em profunda crise, na dura realidade do exílio, o povo começou a rever sua caminhada histórica e a se perguntar: como foi que isso aconteceu? Como tudo voltou ao caos? Por que Deus não nos alertou? Mas a verdade aparece quando se voltam para a pregação profética. A memória e a literatura profética mostram que havia gente alertando, séculos antes, sobre o perigo de um colapso na criação de Deus.

Um dos mais significativos alertas foi dado pelo profeta Oséias, que atuou no reino de Israel em meados do século VIII a. C. Oséias dizia assim:

\begin{abstract}
"Ouçam a palavra de Javé, filhos de Israel! Javé abre m processo contra os moradores do país, pois não há mais fidelidade, nem amor, nem conhecimento de Deus no país. Há juramento falso e mentira, assassínio e roubo, adultério e violência; e sangue derramado se ajunta a sangue derramado. Por isso, a terra geme e seus moradores desfalecem; as feras, aves do céu e até peixes do mar estão desaparecendo. Embora ninguém acuse, ninguém conteste, eu levanto acusação contra você, sacerdote! Você tropeça de dia, o profeta tropeça com você de noite e você faz perecer a sua própria mãe. $\mathrm{O}$ meu povo está morrendo por falta de conhecimento. Porque você rejeita o conhecimento, eu também o rejeitarei como meu sacerdote; você esqueceu a lei do seu Deus; eu também esquecerei os filhos de você" (Os 4,1-6)
\end{abstract}

Este é, sem dúvida, um dos mais antigos textos bíblicos de cunho ecológico. Por isso mesmo, este texto merece um aprofundamento. Numa linguagem de acusação jurídica (rib), Oséias adverte: a corrupção da sociedadehumana está destruindo a ordem e a harmonia da criação de Deus, colocando a Natureza diante de um colapso.

O texto sugere um esquema literário anti-Decálogo. Oséias primeiro aponta a ausência no povo de três atitudes básicas no relacionamento do ser humano com Deus: "não há mais fidelidade ('emet), nem amor (hesed), nem conhecimento (dacat) de Deus" $(4,1)$. A conseqüência desta carência é que a sociedade humana se vê mergulhada em sete situações degradantes no relacionamento humano com o próximo: perjúrio e mentira, assassinato e roubo, adultério e violência, empapando de sangue uma sociedade corrupta e prostituída. 
O que amaldiçoa definitivamente o relacionamento entre o ser humano e a terra é o sangue derramado (cf. Gn 4,10-11). O resultado desta degradação violenta, simbolizada no sangue derramado, é o colapso da Natureza: "A terra geme e seus moradores desfalecem; as feras, aves do céu e até peixes do mar estão desaparecendo" (4,3). Lendo adiante, vemos que Oséias prossegue na sua acusação: "Você, sacerdote! Você tropeça de dia, o profeta tropeça com você de noite e você faz perecer a sua própria mãe. O meu povo está morrendo por falta de conhecimento" (Os 4,4-6). A responsabilidade pelo caos é daqueles que não estão sabendo transmitir ao povo os verdadeiros mandamentos, capazes de manter o relacionamento do ser humano com Deus e com o próximo na verdade, no amor e na paz.

Foi este o primeiro sinal de alerta. É como se Oséias constatasse que um cupim estava entrando, roendo as bases do relacionamento pedido por Deus. Mas ninguém estava lhe dando a devida atenção. Numa intuição muito importante para nós hoje, Oséias faz a ligação entre a integridade da criação de Deus e o comportamento do ser humano. São as degradantes ações humanas, voltadas para seus objetivos gananciosos, que colocam em risco a integridade da criação. Isto foi no século VIII antes de Cristo. O que Oséias diria hoje diante de uma sociedade degradante como a nossa?

No século seguinte, Jeremias retoma a denúncia de Oséias e diz:

\begin{abstract}
"Olhei para a terra: estava sem forma e vazia. Olhei para o céu, e não havia luz. Olhei as montanhas: elas tremiam, e todas as colinas se abalavam. Olhei: não havia mais ninguém, e todas as aves do céu haviam fugido. Olhei: o Carmelo era um deserto, e todas as cidades tinham sido destruídas por Javé e pelo calor da sua ira. Porque assim diz Javé: “O país inteiro vai ser arrasado, mas não vou acabar com ele completamente. É por isso que o país fica de luto, e até o céu, lá em cima, se escurece; pois eu falei, eu decidi, e não vou me arrepender nem voltar atrás" (Jr 4,23-28).
\end{abstract}

Jeremias vê tudo se desintegrando como resultado da corrupção e das injustiças praticadas sobretudo pelos responsáveis que levam consigo o próprio povo. Eles têm uma maneira própria de interpretar os fenômenos da natureza. A seca como fruto da corrupção humana é vista como um castigo de Deus para que o povo tome consciência da sua responsabilidade e comece a inverter o processo da desintegração da natureza. 
Mas as vozes isoladas dos profetas não foram ouvidas. As autorida des, tanto religiosas, civis e militares como os profetas falsos, todos diziam o contrário e as palavras de Oséias, Jeremias e outros caíam no vazio. O cupim foi avançando e de repente veio a tempestade da invasão da Babilônia e do cativeiro. $\mathrm{O}$ telhado veio abaixo e muita gente deu a culpa a Deus.

No mês de agosto de $587 \mathrm{aC}$, Nabucodonosor, rei da Babilônia, mandou destruir a Cidade de Jerusalém (2Rs 25,8-12; Jr 52,12-16). Perderam tudo que, até aquele momento, tinha sido a garantia visível da presença de Deus: O Templo, morada perpétua de Deus (1Rs 9,3), foi incendiado (2Rs 25,9). A Monarquia, fundada para durar sempre (2Sam 7,16), já não existia (2Rs 25,7). A Terra, cuja posse tinha sido garantida para sempre (Gn 13,15), passou a ser a propriedade dos inimigos (2Rs 25,$12 ; \mathrm{Jr} 39,10 ; 52,16)$. O povo perdeu a independência política e tornou-se um grupo étnico, perdido no meio de um império multicultural e multirracial. Os sinais tradicionais da presença de Deus foram destruídos como vaso de vidro que se quebra em mil pedaços. Desapareceu o quadro de referências que tinha orientado o povo até aquele momento.

\section{A situação do povo na crise do cativeiro}

Os textos que melhor ajudam a perceber a situação do povo no cativeiro e a sentir o seu sofrimento são as cinco Lamentações de Jeremias. Sobretudo a terceira e a quinta. A Quinta Lamentação descreve o cativeiro da opressão e da exploração que, de fora, caiu em cima do povo. A Terceira Lamentação descreve o cativeiro da fé e da esperança que, de dentro, estourou na alma do povo.

$\mathrm{O}$ texto da terceira Lamentação retrata bem esse sentimento de desespero:

"Eu sou o homem que conheceu a dor de perto, sob o chicote da sua ira. Ele (Deus) me conduziu e me fez andar nas trevas e não na luz. Ele volve e revolve contra mim a sua mão, o dia todo. Consumiu minha carne e minha pele, e quebrou os meus ossos. Ao meu redor, armou um cerco de veneno e amargura, me fez morar nas trevas como os defuntos, enterrados há muito tempo. Cercou-me qual muro sem saída, e acorrentado, me prendeu. Clamar ou gritar de nada vale, ele está surdo à minha súplica.... Fugiu a paz do meu espírito, a felicidade acabou. Eu digo: 'Acabaram-se minhas forças e minha esperança em Javé’” (Lm 3,1-8.17-18). 
A imagem de Deus que transparece nas entrelinhas deste lamento é a de um carrasco que só quer vingar e machucar. Trágica experiência! Fonte de desespero! Como redescobrir a presença amorosa de Deus na vida? Antigamente, profetas como Samuel e Moisés falavam com Deus e Ele respondia (S1 99,6). Onde está Deus agora? (Sl 42,4.11; 115,2; 79,10; Mq 7,10). Como sair desta situação? Eram estas as perguntas que agitavam as consciências e as conversas de muita gente.

Há também alguns Salmos que ajudam a gente a sentir mais de perto a dor do povo no cativeiro: Salmo 137(136) canta a tristeza do povo no exílio, fora da sua pátria. Salmo 44(43) canta a tristeza do povo que não entende por que foi tão duramente atingido. Salmo 74(73) descreve o terrível massacre do povo e a destruição do Templo. A história da destruição de Jerusalém e da prisão do povo está descrita no livro dos Reis (2Rs 24,1 a 25,30$)$ e no livro de Jeremias (Jr 52,1-34). Uma outra descrição está no livro das Crônicas $(2 \mathrm{Cr} 36,1-21)$.

Lendo as lamentações e os salmos, podemos sentir um pouco da crise manifestada na opressão, na dor e no desânimo do povo no cativeiro. Humanamente falando, não havia saída. Tudo acabou. Como diz o canto de carnaval: "Tristeza não tem fim, Felicidade sim!" Acabou-se a esperança que vinha de Javé. Já não sei mais o que é ser feliz (Lm 3,17-18). Estavam sem futuro. $\mathrm{O}$ poder ameaçador do império matava na raiz qualquer tentativa de revolta. Seria esmagada sem dó nem piedade! Só mesmo apoiado e animado por um poder maior que o poder opressor.

\section{O início da nova leitura do passado abre o futuro}

No exílio, diante da exuberância dos festivais criacionais babilônicos, muitos dentro do povo diziam: "Deus nos abandonou" (Jr 33,23; Is 40,27; 49,14). "Acabou-se a esperança que vinha de Deus" (Lm 3,18). Este desespero nasceu do fato de eles terem identificado Deus com os sinais referenciais da presença divina. Desaparecendo os sinais, desaparecia o próprio Deus. Perderam a foto e pensavam que com ela Deus tivesse desaparecido. O profeta Jeremias ajudou o povo a perceber a presença de Deus de outra maneira. Ele dizia: "Temos muito motivo de esperança!" Perguntavam: "Que motivo?" Respondia: "O sol vai nascer amanhã!" Jeremias recuperou a lógica imutável da natureza como manifestação de Deus:

\footnotetext{
"Assim diz Javé, aquele que estabelece o sol para iluminar o dia e ordena à lua e às estrelas para iluminarem a noite... aquele cujo nome é Javé dos exércitos: quando essas leis falharem diante de mim - oráculo de Javé - então
} 
o povo de Israel também deixará de ser diante de mim uma nação para sempre" (Jr 31,35-36; cf Jr 33,19-21).

O movimento ecológico tem muito a nos dizer. Sem dúvida é um sinal profético para o momento em que vivemos.

Esta maneira de apresentar a ação criadora de Deus transparece também num texto elaborado pelo profeta Ezequiel, escrito lá mesmo, na Babilônia. Ezequiel tem a visão do vale dos ossos secos (Ez 37,1-14). Embranquecidos pelo calor do sol, os ossos são um símbolo eloqüente da degradação e da morte, imagem simbólica de uma situação de colapso total, quando não há mais nenhuma esperança. Tal era a situação que vivia o povo no cativeiro. Na sua visão, Ezequiel diz que aqueles ossos sem vida reviveram pelo poder criador do Espírito de Deus que soprou sobre eles. Os ossos voltaram à vida. O povo certamente renascerá!

No meio desta crise, surge o profeta anônimo cujos oráculos foram preservados no livro do profeta Isaías. Este profeta trouxe novas imagens para expressar o relacionamento com Deus: Os exilados judeus viviam desenraizados na imensidão do império babilônico (587 a 535) e persa (535 a 332). Sentiam que estavam num perpétuo exílio. Como tantos exilados e migrantes de hoje, o único espaço de uma certa autonomia e liberdade que ainda sobrava para eles era o espaço familiar: o pai, a mãe, o marido, a esposa, os filhos, o mundo pequeno da família, a "casa". Todo o resto que antes fazia parte da vida já não existia: a organização mais ampla da tribo, a posse da terra, o templo, as peregrinações, o culto, o sacrifício, o sacerdócio, a monarquia. Nada disso tinha sobrado. Ora, em vez de achar que Deus tivesse desaparecido, foi exatamente neste espaço reduzido e enfraquecido da família, da comunidade, da "casa", que eles reencontraram a presença de Deus. A nova imagem de Deus reflete este ambiente familiar da casa, pois Deus é apresentada por eles como Pai (Is 63,16; 64,7), como Mãe (Is 46,3; 49,1516; 66,12-13), como Marido (Is 54,4-5; 62,5), como parente próximo (ou irmão mais velho) (Is 41,14; 43,1). O Deus que antes estava ligado ao Templo, ao sacerdócio, ao culto oficial, à Monarquia, agora está perto deles, “em casa". Uma casa pequena, quebrada e, humanamente falando, sem futuro; Mas Casa, e não Templo. Não usaram as imagens religiosas tradicionais, mas sim as imagens tiradas da vida familiar e comunitária de cada dia. Eles, por assim dizer, humanizaram a imagem de Deus e sacralizaram a vida como o espaço do reencontro com Deus. "Realmente, tu és um Deus que se esconde, Deus de Israel, Deus salvador!" (Is 45,15). Ele se esconde e se abriga onde antes ninguém o procurava: em casa, no relacionamento diário familiar e comunitário, no meio do povo exilado e excluído! 


\section{Umas palavras de conclusão}

O Livro das Origens (Gn 1-11) foi elaborado por um pequeno grupo de exilados que viviam na maior cidade da época. Cidade que transpirava poder e força. $\mathrm{Na}$ época do exílio Nabucodonosor estava construindo sua enorme torre que dominava toda a paisagem da cidade. A criatividade deste pequeno grupo foi capaz de, em meio ao que havia de maior demonstração de poder e fama de Nabucodonosor, ter a coragem de pensar, dizer e escrever: "Não era para ser assim!" O que Deus queria era justamente o oposto do que eles viam na grande cidade de Babilônia. A torre de Nabucodonosor simbolizava, para eles, a arrogância e a confusão dos projetos humanos, conforme relata o último episódio no Livro das Origens, conhecido como "a torre de Babel" (Gn 11,1-9). Com suas reflexões, os exilados conseguiram descobrir um novo olhar sobre a cidade e a criação de Deus.

Gostaria de concluir buscando o exemplo de um olhar sobre a natureza que, infelizmente, nós perdemos. Orlando Villas Boas, um sertanista que morou muito tempo entre os índios no Xingu, conta este pequeno episódio:

"De todas as histórias contadas pelos índios, a mais surpreendente foi nascida de uma conversa com Arru, um índio de meia-idade que, embora não fosse um grande pajé era, sem dúvida, o mais versado nos conhecimentos que transcendem o saber comum, principalmente no campo do sobrenatural. Arru chegara do mato cansado da caminhada e, encontrando-nos na aldeia, sentou-se ao meu lado. Não havia muita coisa a conversar. Seu mundo monótono, neste aspecto, valia pelo que já havia acontecido. Foi por isso que ele, olhando para os lados, para o chão e depois para o céu, disse: - 'Lá é o céu!' 'Eu já sabia!', respondi. - 'Lá é a aldeia dos que morrem.' - 'Eu já sabia'. Depois de um breve intervalo, e de olhar bastante enlevado para o céu, falou: 'Lá no céu do céu...ela está lá!' Fui tomado de surpresa. Céu do céu...O que viria a ser isto? Ela está lá? Ela, quem? A figura de um índio velho? Daí perguntei: 'Quem? Um índio velho que sabe tudo?' - 'Não! (pronunciado com veemência!) somente uma sabedoria!' E com um gesto largo abrangendo o sol e o céu deu-me a idéia de que lá havia somente uma sabedoria que, tal qual a concepção das seitas tibetanas, mantém a harmonia do universo"

\footnotetext{
${ }^{3}$ VILLAS BOAS, Orlando, A arte dos Pajés - Impressões sobre o universo espiritual xinguano. Rio de Janeiro: Globo, 2000, p. 89-90.
} 
O que chama a atenção neste texto é a incapacidade de Orlando em construir um paralelo entre a revelação feita por Arru com nossas tradições bíblicas sobre a Criação e a Sabedoria de Deus criando, sustentado e harmonizando todo o Universo. Sinal de que nós, cristãos ocidentais simbolizados na figura de Orlando, perdemos alguma coisa.

Precisamos, a partir de nossas tradições bíblicas, recuperar hoje este olhar tão antigo de Arru. Foi no contato renovado com a natureza que os profetas redescobriram o alcance libertador da fé no Deus Criador. Foi mergulhado no cativeiro, relendo os sinais e alertas deixados pelos profetas, que os exilados elaboraram o Livro das Origens. É disso que nós precisamos hoje: de um novo olhar para entender de um outro modo, bem possível, nosso relacionamento com a Terra e com as narrativas bíblicas sobre a Criação. Precisamos redescobrir a grande Sabedoria que move tudo, mantendo a harmonia de todo o universo e que se revela de mil maneiras na natureza e no cotidiano da nossa vida. Onde e como poderemos adquirir este novo/velho olhar?

\title{
Resumo
}

O objetivo deste artigo é fornecer elementos para uma espiritualidade ecológica. Minha proposta é mostrar que a Teologia da Criação, presente no Livro das Origens (Gn 1 a 11), tem sua origem na pregação profética. Embora haja elementos desta Teologia da Criação na profecia em geral, neste artigo vou destacar a pregação de Oséias, do século VIII a.C. e a de Jeremias, do século VII a.C. Esta pregação profética foi relida pelo povo de Deus ao buscar uma saída para a crise vivida no exílio da Babilônia (598538 a.C.), época em que o Livro das Origens foi redigido.

Palavras-chave: Ecologia, Espiritualidade, Profecia, Crise.

\begin{abstract}
The aim of this article is to provide elements for an ecological spirituality. I intend to show that the Theology of Creation in the Book of Origins (Gn 1 to 11), arose from the prophetic preaching. Although there are elements of the Theology of Creation in prophecy as a whole, in this article I will stand out Hosea's preaching from the VIII century b.C., and Jeremiah's one from the VII century b.C. This prophetic preaching was re-read by God's people when they look for a way out of the crisis they had lived in the Babylon exile (598-538 b.C.). The Book of Origins was written during this period.
\end{abstract}


Keywords: Ecology, Spirituality, Prophecy, Crisis.

\section{Francisco Orofino}

Professor de Teologia Bíblica no Instituto de Teologia Paulo VI Nova Iguaçu, RJ Diretor Nacional do Centro de Estudos Bíblicos (CEBI) Assessor do Iser Assessoria E-mail: forofino@uol.com.br

Comunicação Recebida em 06/03/11 Comunicação Aprovada em 05/04/11 